This item was submitted to Loughborough's Research Repository by the author.

Items in Figshare are protected by copyright, with all rights reserved, unless otherwise indicated.

\title{
What is the relationship between long working hours, over-employment, under-employment and the subjective well-being of workers. Longitudinal evidence from the UK.
}

\section{PLEASE CITE THE PUBLISHED VERSION}

http://dx.doi.org/10.1177/0018726714559752

\section{PUBLISHER}

Sage Publications / @ The Authors

\section{VERSION}

AM (Accepted Manuscript)

\section{PUBLISHER STATEMENT}

This work is made available according to the conditions of the Creative Commons Attribution-NonCommercialNoDerivatives 4.0 International (CC BY-NC-ND 4.0) licence. Full details of this licence are available at: https://creativecommons.org/licenses/by-nc-nd/4.0/

\section{LICENCE}

CC BY-NC-ND 4.0

\section{REPOSITORY RECORD}

Angrave, David, and Andy Charlwood. 2015. "What Is the Relationship Between Long Working Hours, Overemployment, Under-employment and the Subjective Well-being of Workers. Longitudinal Evidence from the UK.". Loughborough University. https://hdl.handle.net/2134/16959. 


\title{
What is the relationship between long working hours, over-employment, under- employment and the subjective well-being of workers? Longitudinal evidence from the UK
}

David Angrave* and Andy Charlwood**

*York Management School, University of York

**Corresponding author. School of Business and Economics, Loughborough University. a.charlwood@lboro.ac.uk

Forthcoming in Human Relations

\begin{abstract}
Are long working hours, over-employment and under-employment associated with a reduction in subjective well-being (SWB)? If they are, is the association long or shortlasting? This paper answers these questions through within-person analysis of a nationally representative longitudinal survey from the United Kingdom. The results suggest that long working hours of work do not directly affect SWB, but in line with theories of personenvironment fit, both over-employment and under-employment are associated with lower SWB. However, over-employment is more likely for those who work the longest hours. The duration of the SWB penalty associated with over-employment and under-employment is typically short, but SWB levels tend to remain depressed for those who remain overemployed for two years or more. Results suggest that state and organisational policies that reduce the incidence of long hours working may enhance aggregate well-being levels.
\end{abstract}

\section{Keywords}

Job/employee attitudes, working-time, over-work, long hours, over-employment, underemployment, subjective well-being, Life satisfaction, Job satisfaction 


\section{Introduction}

Working time is an aspect of working conditions that is of central importance to workers, employers and societies. This importance is demonstrated by the widespread statutory regulation of working time; the 40 hour working week has been enshrined in many national legal codes since an International Labour Organisation convention established the principle in 1930 (Lee et al. 2007). Despite this normative and legal support it has been in decline in many advanced industrial economies for at least the last 40 years. Long hours working, defined as working 50 hours a week or more, are common in Japan and South Korea and to a slightly lesser extent, the USA, Australia, New Zealand and the United Kingdom (OECD, 2013; Wooden and Drago, 2007). In this changing context mismatches between actual and preferred working hours, resulting in either over or under-employment are relatively common (see Otterbach, 2010, for the most recent evidence).

In the light of these changes, some academics and popular commentators have inferred that current working time arrangements, and particularly the growth of long hours working are damaging the well-being of workers (see for example Thompson, 2013; Burke and Cooper, 2008; Bunting, 2004; Galinsky et al., 2001; Schor, 1991). Does evidence on the relationship between subjective well-being (SWB) and working time support this inference? Despite the attention paid to issues of both over and under-employment by journalists and commentators, evidence that goes beyond case study or anecdote is limited.

With this in mind the primary contribution of this paper is to examine the relationship between working time and subjective well-being in a nationally representative panel of UK workers. Drawing on person-environment fit theory (P-E fit) we hypothesise that it is not the length of the working week in absolute terms, but the fit between actual and preferred working hours which affects SWB. We partially replicate Wooden et al.'s (2009) Australian study and draw comparisons with the results of Wunder and Heineck's (2013) German study 
on the same theme to examine how well results travel across different social and economic contexts. We also extend the analytical approaches of these studies in two important respects. First, we include an additional measure of psychological well-being that more directly captures experienced affect, the General Health Questionnaire 12 (GHQ12), a widely used diagnostic tool for psychiatric illness (previous studies examined life satisfaction and job satisfaction). Second, we measure the duration of any falls in SWB associated with a mismatch between working time and working time preferences, following the approach developed by Clark and Georgellis (2013) and Clark et al. (2008).

\section{Theory, literature and hypotheses}

Over-employment

Widespread concern that long working hours might be a source of stress is reflected in an extensive body of popular literature and journalism on the subject (e.g. Thompson, 2013; Burke and Cooper, 2008; Bunting, 2004; Galinsky et al., 2001; Schor, 1991). However, whilst these authors tend to take the position that long working hours are bad for employee and societal well-being, the academic literature suggests more nuanced relationships. The relationship between employee working time preferences and working time is an aspect of the fit between employee needs and preferences, and job characteristics (P-E fit). Theories of P-E fit predict that employee job performance and well-being will be higher where P-E fit exists, and that misfit between preferences and job characteristics will be particularly significant for employee well-being and job satisfaction (Kristof-Brown et al., 2005: 283). Where misfit occurs, the un-met need (in this case, the need for more non-work time) becomes a source of stress, thus reducing subjective well-being (Friedland and Price, 2003: 35; Feldman, 1996: 391). 
Empirical evidence tends to support this prediction, but much of the empirical evidence suffers from methodological limitations. Popular and journalistic writing on the subject (e.g. Bunting, 2004) is based largely on anecdotes gleaned from research methods likely to find evidence of negative effects. Studies based on cross-sectional data (e.g. Wilkins, 2007) or longitudinal data that does not utilize within-person analysis (e.g. Friedland and Price 2003) may be biased by failure to account for time invariant individual characteristics. To overcome this bias it is necessary to use longitudinal data to conduct analysis of within-person change in SWB as the fit between working time and working time preferences changes.

Only two studies utilize this type of data and methods (Wunder and Heineck, 2013; Wooden et al., 2009). Research from Australia, based on the Household, Income and Labour Dynamics in Australia Survey suggested that men working 35 hours a week who were overemployed reported lower job satisfaction, while over-employed men who worked 41 or more hours a week also reported lower life satisfaction. Over-employed women also reported lower job satisfaction and lower life satisfaction (Wooden et al., 2009: 163 - 165). In contrast evidence, from the German Socio-economic Panel, found no relationship between overemployment and life satisfaction (Wunder and Heineck, 2013).

Therefore although the robust empirical evidence on this matter is split theory would lead us to expect that the un-met need for more non-work time among those experiencing overemployment will be a source of stress that will result in lower levels of SWB, so there will be a negative relationship between over-employment and indicators of SWB.

Hypothesis 1: Over-employment will be associated with lower levels of subjective well-being. 


\section{Under-employment}

Changing labour market conditions since the great financial crisis of 2008 have bought concerns about the damaging effects of under-employment on worker well-being to the forefront of public debate (e.g. Chakrabortty, 2013). Once again P-E fit would lead us to expect that under-employment results in needs not being met, for example either financial needs or work-related social needs, or the need to maintain work-related social identities. These un-met needs then become a source of stress, reducing SWB. The limited evidence generally supports this proposition. Wooden et al. (2009) found that once the size of the gap between actual and preferred hours was taken into account, there was a negative relationship between under-employment, job satisfaction and life satisfaction, although the relationship was smaller than that between over-employment and SWB. Wunder and Heineck (2013) also found that the under-employed had lower life satisfaction, with the size of the effect relatively greater than that found by Wooden and his colleagues.

Hypothesis 2: Under-employment will be associated with lower levels of subjective well-being.

No existing study investigates the duration of SWB penalties associated with either over or under-employment. This omission is significant, because revised set-point theory (Diener et al. 2006) and its supporting evidence base suggests that only a limited number of events, notably unemployment (Lucas et al., 2004) and the onset of disability (Lucas, 2007) have negative effects on SWB that persist for more than a couple of years. Most events only effect SWB for a matter of months (Suh et al., 1996). The existing evidence on worker responses to working time mismatches suggests that individuals take action to protect their well-being, changing jobs or more commonly adapting preferences (Reynolds and Aletraris, 2006). Even 
if working time or preferences do not change, individuals will become habituated to the source of stress, so SWB return to a set-point. The pertinent question for this study is whether over or under-employment move the set-point so that SWB remains permanently lower, or whether working time mismatches are experienced as more everyday events, which workers adapt to rapidly. This is important because the negative consequences of a working time mismatch will be less if the effects are short-lived. Broadly then, revised set-point theory and related evidence would lead us to expect that workers will adapt to spells of over or underemployment relatively quickly.

Hypothesis 3: Any negative relationships between over or under-employment and SWB will be relatively short-lived, because workers either resolve the mismatch or adapt to cope with it.

\section{Data and Methods}

Data comes from waves 1 to 18 of the British Household Panel Survey (BHPS). The BHPS began in 1991 with a stratified random sample comprising residents of 5,538 households aged 16 and over. A further 2,887 households from Scotland and Wales were added in 1999, along with 1,979 households from Northern Ireland in 2001. Automatic replenishment rules mean that with the exception of new immigrants, who arrived in the country after the study commenced, the survey should have remained broadly representative of the population from which it was drawn. At least one adult member at $74 \%$ of all in-scope selected households agreed to an interview at wave one. The annual re-interview rates for the main sample, averaged around 95\% (Taylor et al., 2010).

Note that our analysis includes all working age individuals (18 - 65) including the employed, self-employed, unemployed and those out of the labour market. This broad sample means that 
we can gain an insight into the meaningfulness of the key results, by comparing the relationships between working time mismatch and SWB to the relationships between SWB, unemployment and health conditions which limit day to day activities.

\section{Measures of working time and working time mismatch}

The BHPS asks respondents about both the hours they actually work, and the hours they would like to work:

"Think about the hours you work, assuming that you would be paid the same amount per hour, would you prefer to work fewer hours, more hours, or the same number of hours?”

Thus we are able to identify whether a respondent's actual and preferred hours are matched, or whether they are over or under-employed. This question has two limitations which need to be kept in mind. First, it imposes the counterfactual "assuming that you would be paid the same amount per hour”, when some salaried respondents will receive the same salary regardless of the hours that they work. This wording may bias results by introducing measurement error unless the common sense of the survey participant leads them to ignore this part of the question if it does not apply to them. Second, it provides no information about the size of the gap between actual and preferred hours. This is important, because evidence from Australia suggests that the size of this gap has a bearing on the relationship between mismatches and SWB (Wooden et al., 2009).

Hours worked were calculated by summing the results of questions on usual weekly working hours, usual hours of paid overtime and, if the respondent had more than one job, questions on usual hours and overtime in the additional job(s). In cases where a respondent had more 
than one job (around 8 per cent of the sample), the design and wording of the questionnaire suggests that most employment related questions should be answered with reference to the main job, but this is not always explicit. Therefore there is scope for measurement error. To account for this, we included a control for respondents with more than one job.

Table 1 summarises responses to the question on hours mismatch for workers (employed and self-employed) according to normal weekly working hours. Overall, 7.25 per cent of men in our sample considered themselves under-employed, with this proportion highest for those working less than 35 hours per week. Over-employment was much more common, with 35.53 per cent of men in our sample reporting over-employment. The equivalent figures for women are 8.07 per cent under-employed and 30.28 per cent over-employed. Note that the probability of being over-employed increases with hours worked, so that, for example, 53.09 per cent of men who worked 50 or more hours a week were over-employed compared to 26 per cent of those who worked a standard working week of between 35 and 40 hours.

Insert Table 1 around here

Most mismatches were typically of short duration (see Table 2), with 75.2 per cent resolved before the next wave of the survey approximately 12 months later, but 12.09 per cent remained mismatched for 1 - 2 years, 4.7 per cent were mismatched for $2-3$ years and 8 per cent were mismatched for more than 3 years.

Insert Table 2 around here 


\section{Job satisfaction}

Job satisfaction is an evaluative judgement about a job made with reference to values, goals and alternatives (Weiss, 2002). It is a good predictor of labour turnover, and as such is an indicator of workers' labour market preferences (Freeman, 1978; Clark, 2001). Respondents were asked, through face-to-face interview: "All things considered, how satisfied or dissatisfied are you with your present job overall?” Replies were on a scale where 1 represents 'not satisfied at all and 7 'completely satisfied'. The distribution of responses to this question are summarised in Table 3. Such single item measures of job satisfaction have adequate convergent validity with multi-item measures (Wanous et al., 1997). Wave one of the survey was not used in the analysis of job satisfaction due to inconsistencies in measurement between waves one and all other waves (Conti and Pudney, 2011).

\section{Life satisfaction}

Life satisfaction represents an imperfect assessment of day to day feelings measured against goals and aspirations (Diener, 1984). It is now well established as a measure of SWB among economists, psychologists and management scholars. It was measured by the question "How dissatisfied or satisfied are you with your life overall?” with responses on a 1-7 scale where 1 represents 'not satisfied at all' and 7 'completely satisfied'. Responses were collected through a self-completion questionnaire. Table 3 reports the distribution of responses to this question. Note that life satisfaction data were only collected in the 1996 to 2000 and 2002 to 2008 waves of the survey.

Insert Table 3 around here 


\section{Psychological well-being}

The inclusion of a measure of psychological well-being helps to overcome some of the limitations of life satisfaction as a measure of SWB, because it is offers a more direct measure of experienced (negative) affect. We used the General Health Questionnaire (GHQ) 12, originally developed as a mental health screening questionnaire, and widely considered to be a robust indicator of an individual's psychological state (Jackson, 2007). Respondents were asked, via self-completion questionnaire about feelings of strain, depression, inability to cope, problems sleeping, lack of confidence, self-worth, inability to make decisions, being useful and enjoying life (with 12 items in total). Responses are on a 1 - 4 scale where 1 means a respondent never experiences the negative feeling/symptom described above and 4 indicates that they experience it all the time. Responses were reverse scaled, so that a positive score indicates higher levels of psychological well-being, and the response range rescaled to $0-3$, so that a 0 represented the lowest well-being score achievable. The twelve items were then combined to create a psychological well-being scale which runs from 0 - 36. To convey an idea of the distribution of responses, in Table 3, we divide the response to this scale by the number of items and round to the nearest whole number.

\section{Methods}

First we categorise workers into discrete groups depending on the number of hours they normally worked in a week, and whether those hours were less than, matched to or more than their preferred hours (as per Table 1). These categories differ for men and women, to reflect the fact that part-time employment is much more common among women. We then examined the relationship between these categorical variables and our measures of SWB using the following model: 
$S W B_{i t}=\mu_{i}+X_{i t} \beta+Z i t \gamma+\varepsilon_{i t}$

Where $S W B_{i t}$ is a measure of subjective well-being for individual $i$ at time $t, \mu_{i}$ are individual specific constants, $X_{i t}$ is a measure of whether or not there is a mismatch between actual and preferred working hours, $Z_{i t}$ captures other time-varying covariates that might influence subjective well-being and $\varepsilon_{i t}$ is an error term. The inclusion of $\mu_{i}$ denotes the use of a fixed effects estimator, which examines the relationship between changes in SWB and changes in the covariates within individuals, so controlling for time invariant individual characteristics. We adopted this approach because previous research (and our own preliminary analysis) suggested that the results of pooled cross-sectional regression models are biased upwards because key independent variables are correlated with unobserved time invariant individual characteristics (Wooden et al., 2009: 169; Ferrer-i-Carbonell and Frijters, 2004).

\section{Control variables}

The covariates captured by $Z_{i t}$ are measures of age (dummy variables for the age categories $<25,25$ - 34, 34 - 49 and 50 and older), whether the respondent has registered as having a disability; whether they have a health condition which limits day to day activities; ${ }^{1}$ married or co-habiting; whether the respondent is a parent to dependent children or living with a partner who has dependent children resident in the household; occupation measured at the one digit standard occupational classification level; whether the respondent has more than one job; survey wave; and the natural log of gross real equivalised household income including welfare payments. ${ }^{2}$ An additional control for whether or not another household member was present for the interview was included in the analysis of job satisfaction (because data were collected through face-to-face interview, see Conti and Pudney 2011). Descriptive statistics for all variables can be found in Table A1 below. 
Note that the models used in two previous studies of working time mismatch (Wooden et al., 2009; Friedland and Price, 2003) include a measure of SWB in the previous wave of the survey to control for state dependence. We omitted this additional control for two reasons. First, if included in model (2) it masks any associations between SWB and an hours mismatch in the previous wave of the survey. Therefore omitting it from model (1) provides consistency across the two models. Second, preliminary analyses suggested that the additional control had very little impact on the overall results (details of these analyses can be found in the online technical appendix that accompanies this article).

\section{Adaption to well-being loss}

To investigate the duration of any changes in SWB associated with over or underemployment, we dispensed with discrete categories as used in the regressions in Table 4, and examined the average association between over and under-employment and SWB regardless of hours. This was necessary because of the limited number of observations where an individual remained mismatched for more than one year while participating in consecutive survey waves (see Table A2). We then followed the approach set out by Clark and Georgellis (2013: 500):

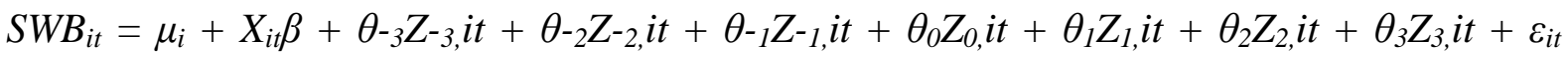

To investigate whether SWB adapted to mismatches, we included lag and lead dummy variables in fixed effects regressions, where the dummy variables capture both whether or not an individual would be mismatched in (a) 3 years' time, 2 years' time and 1 year's time (lags) $\theta_{-3} Z{ }_{-3, i t}$ etc.; (b) at time $t: \theta_{0} Z_{0}$ it; and (c) if they remained mismatched 1 year later, 2 years later and 3 years later (leads) $\theta_{3} Z_{3, i t}$ etc. The dummy variables for the period prior to 
mismatch (lags) will capture whether SWB falls in anticipation of the mismatch. The dummy variables for the period after the initial mismatch (leads) will capture whether SWB adapts to the mismatch. Where there is no evidence of anticipation, all of the values of $\theta-_{-1}$ to $\theta-_{-3}$ will be about zero. Where there is no evidence of adaption the values $\theta_{1}$ to $\theta_{3}$ will be about the same negative number. Because we include the individual fixed effect, we are following the same individual as they approach mismatch (lags) and for the duration of that spell of mismatch (leads). Note that we only investigate adaption in the 24.8 per cent of mismatches where the respondent remained mismatched for more than 1 wave of the survey (see Table 2). Our preliminary analyses found that when mismatches were resolved, SWB levels typically returned to pre-mismatch levels.

Responses from men and women were analysed separately. Models were estimated using the ordinary least squares (OLS) approach, with the xt survey commands in STATA 13 to compute standard errors that take into account the complex survey design of the BHPS and the negative skew of our SWB variables (Stata 2009). Note that the categorical nature of our job and life satisfaction variables means that OLS regression is technically inappropriate; ordered logit or probit models should be used instead. Although the BUC estimator (Baetschmann et al., 2011) offers a consistent method of estimating ordered logit models with fixed effects, there is as yet no established method for estimating marginal effects or relative risk ratios. In the absence of such a method it is difficult to interpret the results. Because it is important to be able to judge the relative magnitude of the results and because the biases that arise from the assumption of cardinality implicit in the OLS estimator are relatively minor compared to biases arising from failure to account for individual fixed effects (Ferrer-iCarbonell and Frijters, 2004: 655), we have estimated OLS models with fixed effects.

\section{Results}


Note first that all three SWB measures were standardised before analysis so the original mean of each variable has a value of 0 , while the value of 1 is given to the point in the distribution that is 1 standard deviation higher than the original mean. Therefore a coefficient with the value of 1 signifies that a 1 unit change in an independent variable is associated with a 1 standard deviation increase in the SWB score (standard deviations are summarised in Table $3)$.

Tables 4 and 5 around here

\section{Over-employment}

Over-employment was associated with lower levels of SWB. Among men (Table 4), becoming over-employed was associated with a statistically significant decline in job and life satisfaction. For example, becoming over-employed while working 40 - 49 hours a week was associated with a decrease in job satisfaction of around one quarter of a standard deviation and a decline in life satisfaction and psychological well-being of around one tenth of a standard deviation. These negative relationships were of a similar magnitude regardless of hours worked.

Among women (Table 5), over-employment was associated with a decrease in job satisfaction of just over one quarter of a standard deviation among those who work 35 - 40 hours a week or less, rising to 0.40 of one standard deviation for women who work more than 50 hours a week. The negative relationships between over-employment, life satisfaction and psychological well-being were apparent for all over-employed women, but were greatest for those working 41 - 49 hours a week. Women in this group who became over-employed experienced a decline in psychological well-being of one fifth of a standard deviation and a 
decline in life satisfaction of 0.17 of a standard deviation. Thus results provide support for Hypothesis 1.

\section{Under-employment}

Men who became under-employed and worked 35 - 40 hours a week experienced lower job satisfaction, lower life satisfaction and lower psychological well-being. The size of these relationships was comparable to those between over-employment and SWB. Men who worked less than 35 hours a week and became under-employed also experienced lower life satisfaction. However, in contrast to all other key results, this finding was somewhat sensitive to model specification and sample; alternative specifications suggested a smaller relationship that was not statistically significant. There were no associations between becoming underemployed and lower SWB for men who worked more than 40 hours a week.

By contrast, women who worked fewer than 35 hours a week and became under-employed experienced lower levels of psychological well-being and life satisfaction. The magnitude of these relationships was typically around half that of relationships between over-employment and SWB. Women who worked very long hours (50+) and who were under-employed also experienced lower levels of SWB on all three indicators. Overall then, these results provide some support for Hypothesis 2; under-employment is associated with lower SWB levels, but only among women who work fewer than 35 hours or more than 50 hours a week and men who work 35 - 40 hours a week.

There is then evidence of the associations between working time mismatches and SWB put forward in hypotheses one and two. To extend our analysis further, do these associations have significance in quantitative terms? One way to answer this question is to compare the results with the associations between SWB and (a) unemployment and (b) a health condition which limits day to day activities; both events which have been found to have a significant negative impact on the lived experiences of those who suffer them. If we make these 
comparisons for over-employed men working 41 - 49 hours a week, we see that the negative relationship between over-employment and psychological well-being for this group (-0.11) is just less than half of that for unemployment $(-0.26)$ and just over a quarter of that for a serious health condition $(-0.41)$. The size of the negative relationship between overemployment and life satisfaction (-0.098) is about two fifths of that of unemployment (0.241) and about one third of that of a serious health condition (-0.29).

For over-employed women, also working 41 - 49 hours a week, the negative relationships between over-employment and SWB are relatively greater. Here, the over-employment psychological well-being relationship (-0.20) is around 60 per cent of the unemployment psychological well-being relationship (-0.33), while it is just less than half that of a serious health condition $(-0.43)$. The over-employment - life satisfaction relationship $(-0.17)$, is greater than the life satisfaction - unemployment relationship (-0.14) but not statistically significant) and around three fifths of the life satisfaction - serious health condition relationship (-0.29).

Turning to results for under-employment, men who are underemployed (and who worked 35 - 41 hours or less a week) experienced a drop in life satisfaction, which is around two fifths of the drop experienced by the unemployed. Psychological well-being also declined by around half the amount associated with unemployment. For under-employed women, working less than 35 hours a week the drop in life satisfaction associated with underemployment was very similar to the drop in life satisfaction associated with unemployment. However, the decline in psychological well-being experienced was around a third of that associated with unemployment.

Does SWB adapt to over and under-employment? 
Insert Figures 1 and 2 around here.

In considering this issue it is important to remember that three quarters of mismatched respondents resolved their mismatch before the next wave of the survey, and for this group, SWB levels returned to pre-mismatch levels within 12 months. Results examining whether there was adaption to over and under-employment for the quarter of respondents, who remained mismatched for over a year are reported in graph form in figures 1 and 2 (full regression results are available in the online technical appendix). Note first that SWB only dipped in the year prior to mismatch among over-employed men and women, who experienced slightly lower job satisfaction (of -0.07 of a standard deviation for men and -0.05 of a standard deviation for women) around 12 months prior to becoming over-employed. Although figure 1 suggests that life satisfaction was lower for under-employed men in the years before under-employment, these results fall short of statistical significance. Second, to the extent that there is a negative relationship between under-employment and SWB, adaption was typically rapid, with SWB recovering to something approximating premismatch levels within 12 months.

By contrast, adaption to over-employment was only partial. Job satisfaction levels returned to and remained at the slightly lower levels that they were at a year prior to the overemployment spell. Other SWB indicators improved in comparison to the level they were at when over-employment was first experienced, but did not always fully recover to premismatch levels. For example, on average the psychological well-being of men who experienced over-employment dropped by 0.12 of a standard deviation. Those who remained over-employed three years later (7.5 per cent of men who experienced over-employment), had average psychological well-being levels that were 0.06 of standard deviation lower than men whose hours and preferences matched. For women, the average drop in psychological 
well-being in the year they became over-employed, was 0.13 of a standard deviation. Those still over-employed three years later (7.3 per cent of over-employed women) experienced psychological well-being levels 0.10 of a standard deviation lower than those whose hours and preferences matched. Life satisfaction levels were also 0.09 of a standard deviation lower.

Overall then, this evidence partly contradicts Hypothesis 3; workers' SWB does not always fully adapt to spells of over-employment. The minority of the over-employed (around 12.5 per cent of over-employed respondents) who remained over-employed for 2 or more years continued to experience a small but significant SWB penalty. By contrast, levels typically returned to pre-mismatch levels within 12 months for the under-employed.

\section{Sensitivity analyses}

To test whether our results were biased by panel attrition we followed the procedure set out by Verbeek and Nijman (1992) and Wooden and Li (2014) by estimating models with a control for whether a respondent failed to participate in the next wave of the survey. The impact of the attrition control was minor and statistically insignificant.

Approximately 15 per cent of the initial sample was not used in the regression analyses, because of missing values on one or more of the covariates. Following the standard assumptions, this should not be a source of bias because item non-response is a random process. Sensitivity analyses generally supported this assumption; with the exception mentioned above, key results were not sensitive to changes in the covariates included in the model and associated changes in the size of the sample. Neither were the key results changed by exclusion of respondents who had more than one job.

\section{Discussion and conclusions}


This study has examined the relationship between working time and three measures of SWB; job satisfaction, life satisfaction and psychological well-being (negative effect). In the context of widespread popular concern about the damaging effects of long hours of work on wellbeing we have found that, in line with predictions derived from person-environment fit theory, long working hours are not associated with lower levels of SWB. SWB only falls if there is a mismatch between actual and preferred hours. Specifically, in line with our first hypothesis, over-employment is associated with a decline in SWB. Note though that the risk of becoming over-employed is greater for those who work long hours. Therefore, although long hours of work do not appear to directly reduce SWB, as critics of long hours working have contended, they are a risk factor. In support of our second hypothesis, there was also evidence that under-employment tends to be associated with lower SWB for women working less than 35 hours a week and men working 35 - 41 hours a week. Adaption theory led us to expect that any decline in SWB associated with an hours mismatch would be quickly reversed (Hypothesis 3). This was generally true; three quarters of mismatches were resolved within a year, and for those over-employed for less than two years, and all mismatches related to under-employment, SWB levels quickly returned to pre-mismatch levels. However, when mismatches related to over-employment went on for more than two years, adaption was only partial; life satisfaction and psychological well-being remained lower than they were prior to the mismatch.

So far, we have been careful to describe the identified relationships between working time mismatch and SWB as associations rather than effects. Theoretically, we would expect a stressor (mismatch) to lower SWB, but there are other potential chains of causality. First, dispositional perspectives (e.g. Rode, 2004) hypothesise that time invariant aspects of genetics and personality largely determine SWB. Within-person analysis controlled for time invariant aspects of personality and genetics. However, we were not able to examine the 
moderating role of these genetic and personality traits. If the dispositional hypothesis is correct, it would mean that the average relationships we identify are being driven by individuals with specific unobserved traits and it is the interaction of the trait and the event that has causal powers.

A second alternative chain of causality would see other (unmeasured) exogenous events acting as stressors, so reducing SWB, with the result that low SWB causes those who work long hours to feel dissatisfied with those hours. Recent qualitative research has pointed to examples of this causal process (Campbell and van Wanrooy 2013). We cannot discount the possibility that this alternative explanation might partially account for our results. However, the overriding point is that regardless of the precise chain of causality, mismatches between actual and preferred hours, particularly mismatches related to over-employment, are a risk factor for SWB, and chances of becoming over-employed rise for those who work long hours.

How do these results compare with other studies in this area? First the finding, that chances of being over-employed and suffering an SWB penalty are greater for those who work the longest hours, fits with recent qualitative evidence published in this journal, that workers who work long hours feel ambivalent about their working time arrangements, and that this ambivalence means that expressed satisfaction with hours can easily give way to dissatisfaction (Campbell and van Wanrooy, 2013).

Second, there is also a remarkable degree of agreement between these results and comparable results from Australia (Wooden et al., 2009). By contrast, there is no SWB penalty for overemployment in Germany (Wunder and Heineck, 2013). One explanation for these contrasting results could be the differences in measures of working time mismatch between the UK and German studies (binary measures of mismatch in the UK compared to a measure of the scale of the mismatch for Germany). However, the Australian study contains both types of 
mismatch measure and the difference persists. Another explanation might be differences in working time regulation between Australia and the UK on one hand and Germany on the other. Specifically, the only statutory form of working time regulation in the UK comes from the European Working Time Directive, which sets a notional maximum 48 hour working week, but workers may opt out of the provisions of the directive if they wish. In Australia, the National Employment Standards specify a 38 hour working week, but voluntary overtime (paid or unpaid) is common. On the face of it, regulation of working time in Germany is not that different to the UK; the extent of statutory regulation is the maximum 48 hour working week stipulated by the European Working Time Directive. However, industry wide collective agreements negotiated between employers' associations and trade unions play a much more important role in regulating working time than is the case in either Australia or the UK, with the result that a much smaller proportion of workers work long hours (Lee et al., 2007) ${ }^{3}$. This then is suggestive of a causal role for collective bargaining in reducing over-employment and the negative effects of over-employment on SWB.

Our results have implications for management and organisations. Organisations may pay a price for asking their workforce to work long hours because by doing so they increase the risk of workers becoming dissatisfied. Job dissatisfaction is likely to increase absenteeism (Scott and Taylor, 1985) and turnover (Freeman 1978; Clark, 2001), both of which impose costs on the employer. This problem could be addressed through organisational flexible working policies that better allow workers to choose their hours, and by recognising and tackling cultures of 'presenteeism' where workers spend long hours at work even though much of the time is not spent productively (e.g. Perlow, 1999). Ultimately though, voluntary action by employers may not tackle the problem, because the financial benefits from workers working longer hours may outstrip the benefits from reducing absenteeism and turnover. 
Therefore the issue may only be tackled effectively through regulatory intervention by the state.

If promoting well-being is an aim of government policy, as it is in Britain (Cameron 2010), then policy makers may wish to take steps to reduce the incidence of long hours working (as this increases the chances of becoming over-employed). Conversely relaxation of the already limited statutory working time regulations (Cameron 2013) may cause aggregate well-being to deteriorate if it results in more long hours working. However, there is no simple relationship between statutory working time regulation and SWB because evidence from Korea suggests that a statutory reduction in working time did not increase SWB (Rudolf, 2014). Policies that allow workers more flexibility to determine their own hours in line with their preferences could also enhance SWB levels. Collective bargaining could be one method for achieving this. An alternative approach might be to extend the individual right to request flexible working, a policy recently introduced by the UK coalition government. However, research suggests that in the UK context, flexibility over hours of work does not result in workers being able to achieve a happy balance between work and non-work commitments (Lott, 2014).

Our results also suggest that hours reductions as an alternative to redundancies might enhance aggregate well-being during periods of inadequate labour demand (because the SWB penalty for under-employment tends to be less than the penalty for unemployment and SWB levels recover more quickly from under-employment than from unemployment). However, on the basis of our results, we cannot say (for example) whether it would be better to create one 30 hour a week job from 6 workers who worked 35 hours a week each giving up 5 hours or one 32.5 hour a week job from 13 workers giving up 2.5 hours each. Our estimates of the underemployment - SWB relationship may also be out of date because the large increase in underemployment since 2008 (Bell and Blanchflower, 2013) may have changed the nature of the 
relationships. Under-employment may also affect some social classes more than others (Lautsch and Scullly, 2007), but our dataset was not large enough to be able to identify whether social class moderated results.

The key strength of this study is the use of broadly nationally representative longitudinal data over an 18 year period that has allowed within-person analysis so controlling for time invariant aspects of personality and values that would bias cross-sectional and betweenperson estimates. Longitudinal data has also allowed us to investigate the extent to which workers' SWB levels recover from over and under-employment. Against this strength, must be set four limitations. First, the lack of a measure of the size of the gap between actual and preferred hours, which limits our ability to compare results with similar German and Australian analyses and to draw policy conclusions. Second, the wording of the question on hours mismatch may also result in measurement error related bias. Third, omitted variables also limit our ability to trace out precise causal mechanisms, for example around the moderating role of personality traits. Fourth, although our data-set has a relatively large number of observations, it is not large enough to be able to investigate the moderating effects of social class or the intersection of social class and gender.

These limitations point to areas where further research to better understand the relationship between SWB, working time and working time preferences would be fruitful. The addition of a question on working time preferences, which mirrors the equivalent German and Australian questions, to the UK Household Longitudinal Study (the larger scale successor of the BHPS), would allow the first, second and fourth limitations to be addressed. Further research could also shed light on the role of different forms of working time regulation in shaping hours of work and the fit between hours and hours preferences. Is it the case that a reduction in working time regulation in the UK would be likely to result in more workers working longer hours (so increasing their risks of over-employment), or is the light touch nature of the 
existing regulation such that repeal of the working time directive would be unlikely to have much of an effect? Research which examines the dynamics underlying the decline of long hours working in the UK over the last 20 years might shed some light on this question. Further research into the German case could also investigate the hypothesis that working time regulation through collective bargaining reduces both the incidence of long hours working and the SWB penalty associated with over-employment. Both would shed light on the potential for state regulatory policy to address the SWB penalties associated with overemployment.

\section{Funding}

This research received no specific grant from any funding agency in the public, commercial, or not-for-profit sectors.

\section{Notes}

1. The question asking whether a respondent had a health condition which limited daily activities was not asked in the 2004 and 2005 waves of the survey, so these waves were excluded from the analysis of model (1). The control for health conditions was omitted from model (2) so that all waves could be included in order to maximise the number of participants who we could follow through consecutive waves.

2. Nominal income values were converted into constant price equivalents using the retail price index measure of inflation. We adjust for household size and composition using the OECD modified equivalence scale, see Hagenaars, de Vos, \& Zaidi, 1994.

3. In 2012, $14 \%$ of Australian workers worked 50 or more hours a week, compared to $12 \%$ in the UK and 6\% in Germany (OECD 2013). 


\section{References}

Bell DNF and Blanchflower DG (2013) Under-employment in the UK Revisited. National Institute Economic Review 224 (May): F8 - F21.

Baetschmann, G, Staub, KE and Winkelmann, R (2011) Consistent estimation of the fixed effects ordered logit model. IZA Discussion Paper 5443, Bonn: IZA.

Bunting M (2004) Willing Slaves: How the Overwork Culture is Ruling Our Lives. London: Harper Perennial.

Burke RJ and Cooper CL (eds) (2008) The Long Work Hours Culture: Causes, Consequences and Choices. Emerald: Bingley.

Cameron D (2010) Speech given by the Prime Minister on well-being, Verbatim transcript downloaded from http://www.number10.gov.uk/news/pm-speech-on-well-being/ on $19^{\text {th }}$ July 2013.

Cameron D (2013) EU Speech at Bloomberg. 1/23/213. Verbatim transcript downloaded from https://www.gov.uk/government/speeches/eu-speech-at-bloomberg on 13th July 2013. Campbell I and van Wanrooy B (2013) Long working hours and working-time preferences: Between desirability and feasibility. Human Relations 66(8): 1131 - 1155.

Chakrabortty, A (2013) Under-employment can be as corrosive as unemployment and it’s on $\begin{array}{lllll}\text { the } & \text { rise. } & \text { Guardian, } & 15^{\text {th }} & \text { April }\end{array}$ (http://www.theguardian.com/commentisfree/2013/apr/15/underemployment-corrosive$\underline{\text { unemployment-on-rise) }}$

A, (2001) What really matters in a job? Hedonic measurement using quit data. Labour Economics 8(2): $223-242$.

Clark A, Diener E, Georgellis, Y and Lucas, RL (2008) Lags and Leads in Life Satisfaction: A Test of the Baseline Hypothesis. Economic Journal 118(529): F222 - 243. 
Clark A and Georgellis Y (2013) Back to the baseline in Britain: Adaption in the British Household Panel Survey. Economica 80: 496 - 521.

Conti G and Pudney S (2011) Survey design and the analysis of satisfaction. The Review of Economics and Statistics 93(3): 1087 - 1093.

Diener E (1984) Subjective Well-Being. Psychological Bulletin 85(3): 542 - 574

Diener E, Lucas, RE and Scollon, CN (2006) Beyond the hedonic treadmill. Revising the adaption theory of well-being. American Psychologist 61(4): 305 - 314.

Feldman, DC (1996) The nature, antecedents and consequences of under-employment. Journal of Management, 22(3): 385 - 407.

Ferrer-i-Carbonell A and Frijters P (2004) How important is methodology for the determinants of life satisfaction? The Economic Journal 114: 641 - 659.

Freeman, R (1978) Job satisfaction as an economic variable. American Economic Review, 68(2): $131-141$.

Friedland DS and Price R (2003) Under-employment: Consequences for the Health and WellBeing of Workers. American Journal of Community Psychology 32(1/2): 33 - 45.

Galinsky E, Kim SS and Bond, JT. 2001. Feeling Overworked: When Work Becomes Too Much. New York: Families and Work Institute.

Hagenaars, A, de Vos, K, \& Zaidi, MA (1994) Poverty Statistics in the Late 1980s: Research Based on Micro-data. Luxembourg: Office for Official Publications of the European Communities.

Jackson, C (2007) The General Health Questionnaire, Occupational Medicine, 64(7): 79. Kristoff-Brown, A, Zimmerman, RD, Johnson, EC (2005) Consequences of individuals’ fit at work: A meta-analysis of person-job, person-organization, person-group and personsupervisor fit. Personnel Psychology, 58(2): 281 - 342. 
Lautsch BA and Scully MA (2007) Re-structuring time: Implications of work-hours reductions for the working class. Human Relations 60(5): 719 - 743.

Lee, S, McCann, D and Messenger, J (2007) Working Time Around the World, International Labour Office: Geneva.

Lott, Y (2014) Working-time flexibility and autonomy: a European perspective on time adequacy. European Journal of Industrial Relations online first doi: $10.1177 / 09568011453604$

Lucas, R, Clark, A, Georgellis, Y, \& Diener, E (2004) Unemployment alters the set-point for life satisfaction. Psychological Science, 15: 8 - 13.

Lucas, R, (2007) Long-term disability is associated with lasting changes in subjective wellbeing: Evidence from two nationally representative longitudinal studies. Journal of Personality and Social Psychology, 92: 717-730.

OECD (Organisation for Economic Co-operation and Development). 2013. OECD Better Life Index. http://www.oecdbetterlifeindex.org/ (downloaded on $5^{\text {th }}$ May 2013).

Otterbach S (2010) Mismatches Between Actual and Preferred Working Time: Empirical Evidence of Hours Constraints in Twenty-One Countries. Journal of Consumer Policy 33(2): $143-161$.

Perlow, LA (1999) Time famine: Toward a sociology of work time. Administrative Science Quarterly 44(1): 57 - 81.

Rode, JC (2004) Job satisfaction and life satisfaction revisited: A longitudinal test of an integrated model. Human Relations 57(9): 1205 - 1230.

Reynolds, J and Aletraris, L (2006) Pursuing Preferences: The creation and resolution of work hour mismatches. American Sociological Review 71(4): 618 - 638. 
Rudolf, R (2014) Work Shorter, Be Happier? Longitudinal Evidence from the Korean FiveDay Working Policy, Journal of Happiness Studies, 15(5): 1139-1163.

Schor JB (1991) The Overworked American: The Unexpected Decline in Leisure. New York: Basic Books.

Scott, KD and Taylor, SG (1985) An examination of the conflicting findings on the relationship between job satisfaction and absenteeism: A meta-analysis. Academy of Management Journal 28(3): 599 - 612.

Stata (2009) Stata Longitudinal-Data/Panel Data, Release 10. Texas: Stata Press

Suh, E Diener, E and Fujita, F (1996) Events and subjective well-being: only recent events matter. Journal of Personality and Social Psychology, 70(5): 1091 - 1102.

Taylor, MF (Ed.), with Brice J, Buck N, \& Prentice-Lane E. (2010). British Household Panel Survey User Manual, Volume A: Introduction, Technical Report and Appendices, Colchester: Institute for Social and Economic Research, University of Essex.

Thompson, D (2013) How Did Work-Life Balance in the U.S. Get So Awful. The Atlantic. http://www.theatlantic.com/business/archive/2013/06/how-did-work-life-balance-in-the-usget-so-awful/276336/ downloaded on $6^{\text {th }}$ May 2013.

Verbeek M and Nijman T (1992) Testing for selectivity bias in panel data models. International Economic Review 33(3): 681-703.

Wanous JP, Reichers AE and Hudy MJ (1997) Overall job satisfaction: how good are singleitem measures? Journal of Applied Psychology 82(2): 247 - 252.

Weiss, HM (2002) Deconstructing job satisfaction: separating evaluations, beliefs and affective experiences. Human Resource Management Review 12: 173 - 194.

Wilkins R (2007) The consequences of under-employment for the under-employed. Journal of industrial Relations, 49: 247 - 75. 
Wooden M and Li N (2014) Panel conditioning and subjective well-being. Social Indicators Research. 117(1): 235 - 255.

Wooden M and Drago R (2007) The changing distribution of working hours in Australia. Melbourne: Melbourne Institute Working Paper No. 19/07.

Wooden M, Warren D and Drago, R (2009) Working Time Mismatch and Subjective WellBeing. British Journal of Industrial Relations 47(1): 147 - 179.

Wunder C and Heineck, G (2013) Working Time Preferences, Hours Mismatch and WellBeing of Couples: Are There Spillovers? Labour Economics, 24: 244 - 252. 
Table 1. Working time mismatch by usual weekly working hours in the BHPS

\begin{tabular}{|l|cccc|}
\hline \multicolumn{1}{|c|}{$\begin{array}{c}\text { Weekly hours } \\
\text { normally worked }\end{array}$} & \multicolumn{3}{c|}{ Type of working time match \% } & \% \\
Under-employed & Matched & Over-employed & Distribution \\
\hline Men & & & & \\
$<35$ & 23.55 & 63.02 & 13.44 & 8.54 \\
$35-40$ & 7.49 & 66.31 & 26.2 & 33.94 \\
$41-49$ & 5.77 & 58.54 & 35.69 & 29.05 \\
$50+$ & 3.66 & 43.25 & 53.09 & 28.47 \\
Sub-total & 7.25 & 57.22 & 35.53 & \\
\hline Women & & & & \\
$<21$ & 18.13 & 73.31 & 8.56 & 23.15 \\
$21-30$ & 10.55 & 70.62 & 18.82 & 17.24 \\
$31-35$ & 8.61 & 62.3 & 29.09 & 3.75 \\
$35-40$ & 3.66 & 59.63 & 36.71 & 33.81 \\
$41-49$ & 2.84 & 51.2 & 45.96 & 14.5 \\
$50+$ & 1.15 & 34.23 & 64.62 & 7.56 \\
Sub-total & 8.07 & 61.65 & 30.28 & \\
\hline
\end{tabular}

Notes: Un-weighted sample of observations with complete information for all covariates used in the regression analysis. This excludes waves 9 and 14 because the question on whether health limits daily activities was not included in these waves.

Table 2. How quickly were working time mismatches resolved?

\begin{tabular}{|l|c|c|c|c|}
\hline & $\begin{array}{c}\text { \% of } \\
\text { Mismatches } \\
\text { resolved } \\
\text { within 12 } \\
\text { months }\end{array}$ & $\begin{array}{c}\text { \% of } \\
\text { Mismatches } \\
\text { resolved } \\
\text { within } \\
\mathbf{1 - 2} \text { years }\end{array}$ & $\begin{array}{c}\text { \% of } \\
\text { Mismatches } \\
\text { resolved within }\end{array}$ & $\begin{array}{c}\text { \% of } \\
\text { Mismatches not } \\
\text { resolved within } \\
\text { 3 years }\end{array}$ \\
\hline Over-employed men & 79.30 & 9.20 & 4.04 & 7.46 \\
\hline $\begin{array}{l}\text { Under-employed } \\
\text { men }\end{array}$ & 60.92 & 22.32 & 4.14 & 12.62 \\
\hline $\begin{array}{l}\text { Over-employed } \\
\text { women }\end{array}$ & 79.60 & 8.98 & 4.13 & 7.29 \\
\hline $\begin{array}{l}\text { Under-employed } \\
\text { women }\end{array}$ & 57.08 & 24.93 & 9.10 & 8.89 \\
\hline Total & 75.22 & 12.09 & 4.65 & 8.03 \\
\hline
\end{tabular}

Base: un-weighted sample of 39,659 observations where mismatch was reported in any of the 18 waves of the survey and who were observed until the mismatch was resolved or up to 3 waves after the mismatch, and who supplied information for all covariates used in the regression analysis (except the question on whether health limited daily activities, which was not used in model (2) in order to maximise the number of observations and waves included). 
Table 3. The distribution of subjective well-being measures in the BHPS

\begin{tabular}{|c|c|c|c|c|}
\hline \multirow{2}{*}{$\begin{array}{c}\text { Job satisfaction* } \\
\text { (among employed \& } \\
\text { self-employed persons } \\
\text { only) }\end{array}$} & \multicolumn{2}{|c|}{ Male } & \multicolumn{2}{|c|}{ Female } \\
\hline & Count & $\%$ & Count & $\%$ \\
\hline 1 & 786 & 1.6 & 636 & 1.41 \\
\hline 2 & 1,360 & 2.86 & 1,003 & 2.26 \\
\hline 3 & 3,226 & 6.79 & 2,451 & 5.53 \\
\hline 4 & 4,313 & 9.08 & 2,594 & 5.85 \\
\hline 5 & 11,216 & 23.62 & 8,865 & 19.99 \\
\hline 6 & 20,870 & 43.94 & 20,818 & 46.95 \\
\hline 7 & 5,749 & 12.11 & 7,983 & 18 \\
\hline Total & 47,523 & 100 & 44,350 & 100 \\
\hline Mean & \multicolumn{2}{|c|}{5.31} & \multicolumn{2}{|c|}{5.54} \\
\hline SD & \multicolumn{2}{|c|}{1.31} & \multicolumn{2}{|c|}{1.27} \\
\hline \multirow{2}{*}{ Life satisfaction $^{* *}$} & \multicolumn{2}{|c|}{ Male } & \multicolumn{2}{|c|}{ Female } \\
\hline & Count & $\%$ & Count & $\%$ \\
\hline 1 & 820 & 2.44 & 1,170 & 3 \\
\hline 2 & 692 & 2.06 & 1,004 & 2.47 \\
\hline 3 & 1,845 & 5.48 & 2,099 & 5.16 \\
\hline 4 & 4,595 & 13.65 & 5,393 & 13.26 \\
\hline 5 & 11,386 & 33.83 & 11,516 & 28.31 \\
\hline 6 & 11,658 & 34.64 & 13,027 & 32.03 \\
\hline 7 & 3,037 & 9.02 & 5,727 & 14.08 \\
\hline Total & 33,653 & 100 & 40,673 & 100 \\
\hline Mean & \multicolumn{2}{|c|}{4.23} & \multicolumn{2}{|c|}{4.40} \\
\hline S.D & \multicolumn{2}{|c|}{1.16} & \multicolumn{2}{|c|}{1.32} \\
\hline Psychological well-being & \multicolumn{2}{|c|}{ Male } & \multicolumn{2}{|c|}{ Female } \\
\hline (GHQ12)*** & Count & $\%$ & Count & $\%$ \\
\hline 0 & 304 & 0.58 & 774 & 1.22 \\
\hline 1 & 1801 & 3.47 & 4091 & 6.44 \\
\hline 2 & 14982 & 28.7 & 24004 & 37.77 \\
\hline 3 & 35142 & 67.28 & 34681 & 54.56 \\
\hline Total & 52,229 & 100 & 63,550 & 100 \\
\hline Mean & \multicolumn{2}{|c|}{25.53} & \multicolumn{2}{|c|}{24.02} \\
\hline SD & \multicolumn{2}{|c|}{5.05} & \multicolumn{2}{|c|}{5.77} \\
\hline
\end{tabular}

Notes: Un-weighted sample of respondents who supplied information for all covariates used in the regression analysis. This excludes waves 9 and 14 because the question on whether health limits daily activities was not included in these waves. * - Wave 1 omitted because of inconsistencies in show card labelling between wave 1 and all other waves. ** The question on life satisfaction was only asked in waves 6 to 10 and 12 to 18 . *** The psychological well-being scores were calculated by dividing the 0 - 36 scale used in the analysis reported below by the number of items in the scale (12) and rounding to the nearest whole number, in order to convey a sense of the distribution of responses succinctly. 
Table 4. The associations between over-employment and under-employment and the subjective wellbeing of men: Fixed effects regression analysis

\begin{tabular}{|c|c|c|c|}
\hline & Job satisfaction & $\begin{array}{l}\text { Psychological } \\
\text { well-being }\end{array}$ & $\begin{array}{c}\text { Life } \\
\text { satisfaction }\end{array}$ \\
\hline Controls & $A L L$ & $A L L$ & $A L L$ \\
\hline Gender & Men & Men & Men \\
\hline $\begin{array}{l}\text { Working time and working time match } \\
\text { (Ref: } 35-40 \text { hours matched) }\end{array}$ & & & \\
\hline$<35$ hours under-employed & $\begin{array}{l}-0.04 \\
(0.05)\end{array}$ & $\begin{array}{l}-0.04 \\
(0.04)\end{array}$ & $\begin{array}{l}-0.10^{*} \\
(0.05)\end{array}$ \\
\hline$<35$ hours matched & $\begin{array}{c}0.17^{* * *} \\
(0.03)\end{array}$ & $\begin{array}{l}0.07^{* *} \\
(0.03)\end{array}$ & $\begin{array}{l}0.08^{*} \\
(0.03)\end{array}$ \\
\hline$<35$ hours over-employed & $\begin{array}{c}-0.24 * * * \\
(0.05)\end{array}$ & $\begin{array}{l}-0.10^{*} \\
(0.05)\end{array}$ & $\begin{array}{c}-0.12 * * * \\
(0.06)\end{array}$ \\
\hline 35-40 hours under-employed & $\begin{array}{c}-0.18^{* * *} \\
(0.03)\end{array}$ & $\begin{array}{c}-0.11^{* * *} \\
(0.03)\end{array}$ & $\begin{array}{l}-0.09 * \\
(0.04)\end{array}$ \\
\hline 35-40 hours over-employed & $\begin{array}{c}-0.31^{* * *} \\
(0.02)\end{array}$ & $\begin{array}{c}-0.13^{* * *} \\
(0.02)\end{array}$ & $\begin{array}{c}-0.11^{* * *} \\
(0.02)\end{array}$ \\
\hline 41-49 hours under-employed & $\begin{array}{l}-0.04 \\
(0.04)\end{array}$ & $\begin{array}{l}-0.06 \\
(0.03)\end{array}$ & $\begin{array}{l}-0.03 \\
(0.04)\end{array}$ \\
\hline 41-49 hours matched & $\begin{array}{c}0.03 \\
(0.02)\end{array}$ & $\begin{array}{c}0.00 \\
(0.01)\end{array}$ & $\begin{array}{l}-0.02 \\
(0.02)\end{array}$ \\
\hline 41-49 hours over-employed & $\begin{array}{c}-0.27 * * * \\
(0.02)\end{array}$ & $\begin{array}{c}-0.11^{* * *} \\
(0.02)\end{array}$ & $\begin{array}{c}-0.10^{* * *} \\
(0.02)\end{array}$ \\
\hline 50+ hours under-employed & $\begin{array}{l}-0.07 \\
(0.05)\end{array}$ & $\begin{array}{c}0.02 \\
(0.05)\end{array}$ & $\begin{array}{l}-0.00 \\
(0.06)\end{array}$ \\
\hline 50+ hours matched & $\begin{array}{l}0.07 * * \\
(0.02)\end{array}$ & $\begin{array}{c}0.03 \\
(0.02)\end{array}$ & $\begin{array}{l}0.05^{*} \\
(0.02)\end{array}$ \\
\hline 50+ hours over-employed & $\begin{array}{c}-0.27 * * * \\
(0.02)\end{array}$ & $\begin{array}{c}-0.11^{* * *} \\
(0.02)\end{array}$ & $\begin{array}{c}-0.11^{* * *} \\
(0.02)\end{array}$ \\
\hline Self-employed & $\begin{array}{c}-0.08^{* *} \\
(0.02)\end{array}$ & $\begin{array}{c}0.02 \\
(0.02)\end{array}$ & $\begin{array}{l}0.07 * * \\
(0.03)\end{array}$ \\
\hline Unemployed & & $\begin{array}{c}-0.26 * * * \\
(0.07)\end{array}$ & $\begin{array}{l}-0.24 * * \\
(0.08)\end{array}$ \\
\hline Working age but not in labour force & & $\begin{array}{c}-0.23^{* * *} \\
(0.05)\end{array}$ & $\begin{array}{c}-0.22 * * \\
(0.07)\end{array}$ \\
\hline Registered disability & $\begin{array}{l}-0.06 \\
(0.04)\end{array}$ & $\begin{array}{c}0.08 * * \\
(0.03)\end{array}$ & $\begin{array}{c}0.13^{* * *} \\
(0.03)\end{array}$ \\
\hline Health affects daily life & $\begin{array}{c}-0.15^{* * *} \\
(0.02)\end{array}$ & $\begin{array}{c}-0.41 * * * \\
(0.02)\end{array}$ & $\begin{array}{c}-0.29 * * * \\
(0.02)\end{array}$ \\
\hline Observations & 47,523 & 52,229 & 33,653 \\
\hline R-squared & 0.03 & 0.03 & 0.03 \\
\hline Number of unique individuals & 8,575 & 9,557 & 7,974 \\
\hline
\end{tabular}

Standard errors in parentheses, ${ }^{* * *} \mathrm{p}<0.001,{ }^{* *} \mathrm{p}<0.01,{ }^{*} \mathrm{p}<0.05$. Controls for log of household income, age, marital status, number of children, the presence of another individual during the interview (job satisfaction only), occupation and wave were included in the models but are not reported here for reasons of space. Full results are available in a further technical appendix available via the journal website. 
Table 5. The associations between over-employment and under-employment and the subjective well-being of women: Fixed effects regression analysis

\begin{tabular}{|c|c|c|c|}
\hline & Job satisfaction & $\begin{array}{l}\text { Psychological } \\
\text { well-being }\end{array}$ & $\begin{array}{c}\text { Life } \\
\text { satisfaction }\end{array}$ \\
\hline Controls & $A L L$ & $A L L$ & $A L L$ \\
\hline Gender & Women & Women & Women \\
\hline \multicolumn{4}{|c|}{$\begin{array}{l}\text { Working time and working time match } \\
\text { (Ref: } 35-40 \text { matched) }\end{array}$} \\
\hline$<21$ hours under-employed & $\begin{array}{l}-0.06 \\
(0.04)\end{array}$ & $\begin{array}{c}-0.10^{* *} \\
(0.04)\end{array}$ & $\begin{array}{c}-0.13^{* *} \\
(0.04)\end{array}$ \\
\hline$<21$ hours matched & $\begin{array}{c}0.02 \\
(0.02)\end{array}$ & $\begin{array}{c}-0.08^{* * * *} \\
(0.02)\end{array}$ & $\begin{array}{l}-0.03 \\
(0.02)\end{array}$ \\
\hline$<21$ hours over-employed & $\begin{array}{c}-0.25^{* * * *} \\
(0.03)\end{array}$ & $\begin{array}{c}-0.20 * * * \\
(0.03)\end{array}$ & $\begin{array}{c}-0.10^{* *} \\
(0.03)\end{array}$ \\
\hline 21-34 under-employed & $\begin{array}{l}-0.07 \\
(0.04)\end{array}$ & $\begin{array}{l}-0.12 * \\
(0.05)\end{array}$ & $\begin{array}{l}-0.16^{* *} \\
(0.06)\end{array}$ \\
\hline 21-34 hours matched & $\begin{array}{c}-0.29 * * * \\
(0.02)\end{array}$ & $\begin{array}{c}-0.16^{* * *} \\
(0.02)\end{array}$ & $\begin{array}{c}-0.10^{* * *} \\
(0.02)\end{array}$ \\
\hline 21-34 hours over-employed & $\begin{array}{c}0.02 \\
(0.07)\end{array}$ & $\begin{array}{l}-0.03 \\
(0.08)\end{array}$ & $\begin{array}{l}-0.14 \\
(0.09)\end{array}$ \\
\hline 35-40 hours under-employed & $\begin{array}{l}0.06 * * \\
(0.02)\end{array}$ & $\begin{array}{c}0.03 \\
(0.02)\end{array}$ & $\begin{array}{c}0.02 \\
(0.03)\end{array}$ \\
\hline 35-40 hours over-employed & $\begin{array}{c}-0.29 * * * \\
(0.02)\end{array}$ & $\begin{array}{c}-0.15^{* * * *} \\
(0.02)\end{array}$ & $\begin{array}{c}-0.11^{* * * *} \\
(0.03)\end{array}$ \\
\hline 41-49 hours under-employed & $\begin{array}{l}-0.23 \\
(0.17)\end{array}$ & $\begin{array}{l}-0.03 \\
(0.18)\end{array}$ & $\begin{array}{l}-0.04 \\
(0.19)\end{array}$ \\
\hline 41-49 hours matched & $\begin{array}{c}0.14^{* * *} \\
(0.04)\end{array}$ & $\begin{array}{c}0.06 \\
(0.04)\end{array}$ & $\begin{array}{l}-0.00 \\
(0.04)\end{array}$ \\
\hline 41-49 hours over-employed & $\begin{array}{c}-0.33^{* * *} \\
(0.03)\end{array}$ & $\begin{array}{c}-0.20 * * * \\
(0.03)\end{array}$ & $\begin{array}{c}-0.17 * * * \\
(0.04)\end{array}$ \\
\hline 50+ hours under-employed & $\begin{array}{l}-0.07^{*} \\
(0.03)\end{array}$ & $\begin{array}{c}-0.11^{* * * *} \\
(0.03)\end{array}$ & $\begin{array}{c}-0.14 * * * \\
(0.04)\end{array}$ \\
\hline 50+ hours matched & $\begin{array}{c}0.10^{* * * *} \\
(0.02)\end{array}$ & $\begin{array}{c}-0.06 * * \\
(0.02)\end{array}$ & $\begin{array}{c}0.01 \\
(0.02)\end{array}$ \\
\hline 50+ hours over-employed & $\begin{array}{c}-0.40 * * * \\
(0.04)\end{array}$ & $\begin{array}{c}-0.16^{* * * *} \\
(0.04)\end{array}$ & $\begin{array}{l}-0.11^{*} \\
(0.04)\end{array}$ \\
\hline Self-employed & $\begin{array}{c}-0.09 * * \\
(0.03)\end{array}$ & $\begin{array}{l}0.06^{*} \\
(0.03)\end{array}$ & $\begin{array}{l}0.10 * * \\
(0.04)\end{array}$ \\
\hline Unemployed & & $\begin{array}{c}-0.33^{* * * *} \\
(0.09)\end{array}$ & $\begin{array}{l}-0.14 \\
(0.10)\end{array}$ \\
\hline Working age but not in labour force & & $\begin{array}{c}-0.19 * * * \\
(0.03)\end{array}$ & $\begin{array}{c}0.07 \\
(0.04)\end{array}$ \\
\hline Registered disability & $\begin{array}{l}-0.02 \\
(0.5)\end{array}$ & $\begin{array}{c}0.15^{* * *} \\
(0.03)\end{array}$ & $\begin{array}{c}0.13^{* * *} \\
(0.03)\end{array}$ \\
\hline Health affects daily life & $\begin{array}{c}-0.11 * * * \\
(0.02)\end{array}$ & $\begin{array}{c}-0.43 * * * \\
(0.016)\end{array}$ & $\begin{array}{c}-0.29 * * * \\
(0.02)\end{array}$ \\
\hline Observations & 44,350 & 63,550 & 40,673 \\
\hline R-squared & 0.04 & 0.03 & 0.02 \\
\hline Number of unique individuals & 8,372 & 11,329 & 9,441 \\
\hline
\end{tabular}

Standard errors in parentheses, ${ }^{* * *} \mathrm{p}<0.001,{ }^{* *} \mathrm{p}<0.01,{ }^{*} \mathrm{p}<0.05$. Controls for log of household income, age, marital status, number of children, the presence of another individual during the interview (job satisfaction only), occupation and wave were included in the models but are not reported here for reasons of space. Full results are available in a further technical appendix available via the journal website. 
Figure 1. Under-employment mismatches and subjective well-being: Analysis of lags and leads

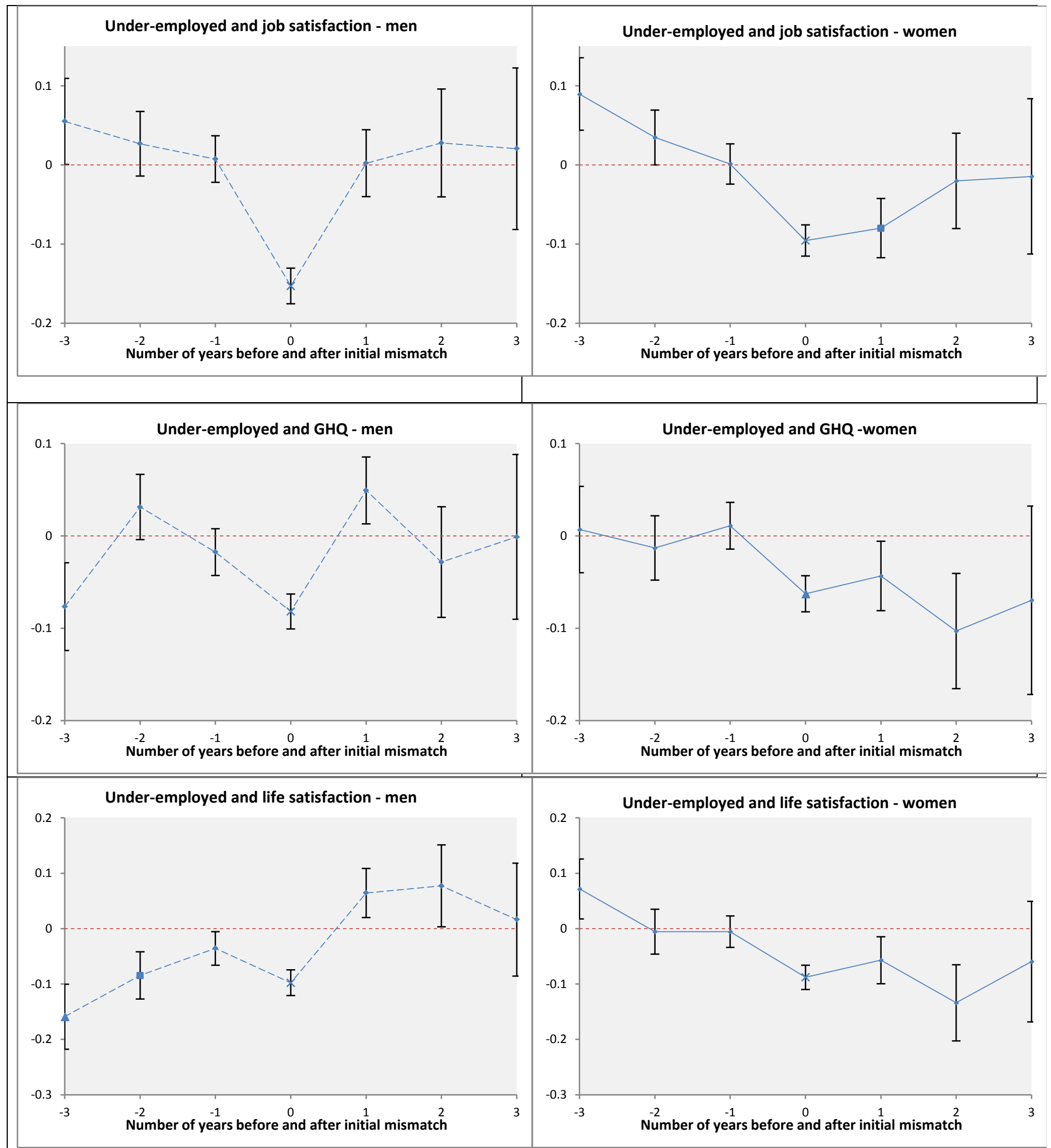

Based on a regression model with controls for unemployment, self-employment, not in the labour market, log of household income, age, marital status, number of children, the presence of another individual during the interview (job satisfaction only), occupation and wave. Full results available Full results are available in a further technical appendix available via the journal website.

Standard errors are indicated by vertical black lines. Level of significance indicated by symbols: $\times \mathrm{p}<0.001, \Delta \mathrm{p}<0.01, \square \mathrm{p}<0.05$ 
Figure 2. Over-employment and subjective well-being: Analysis of lags and leads

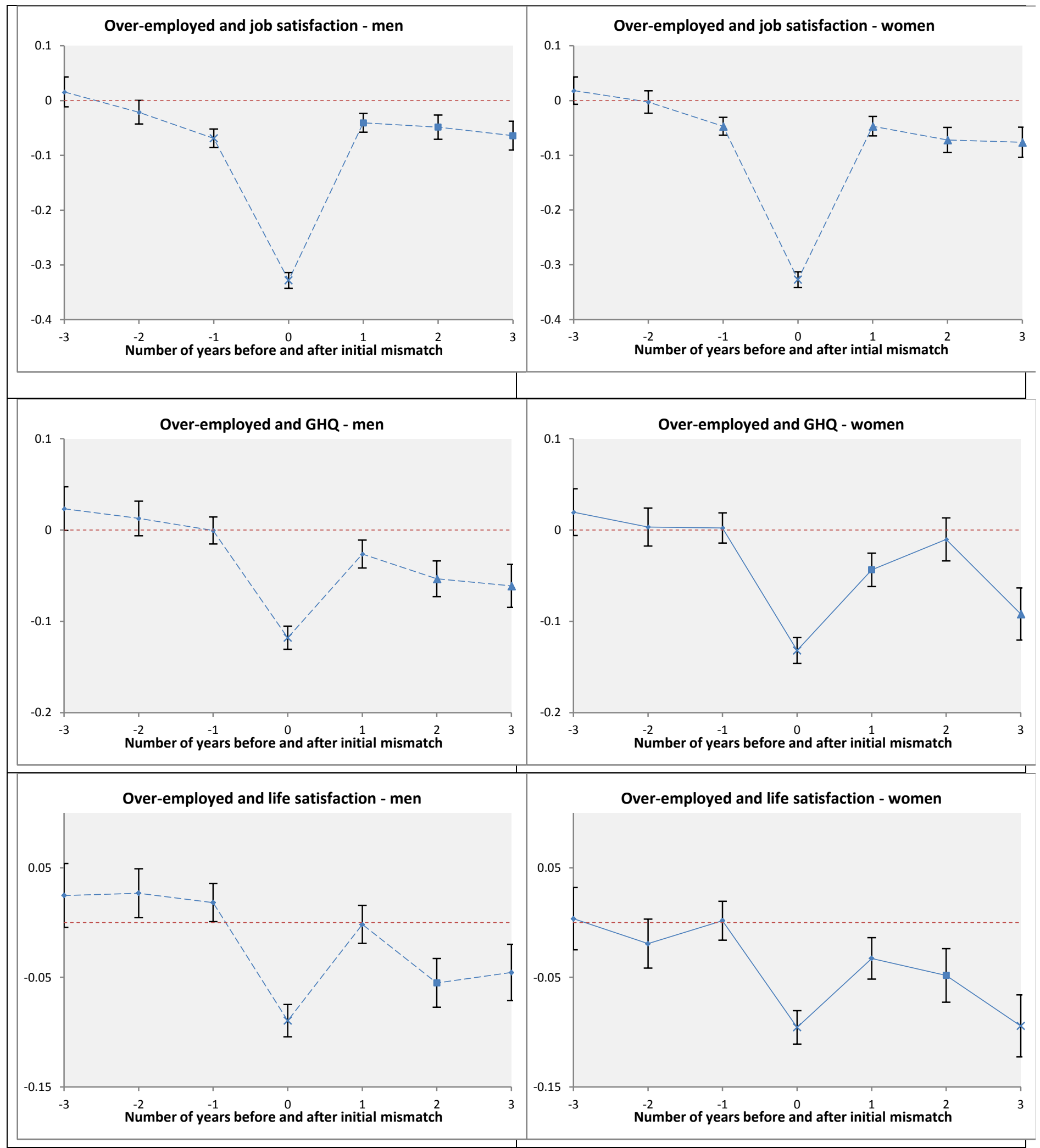

Based on a regression model with controls for unemployment, self-employment, not in the labour market, log of household income, age, marital status, number of children, the presence of another individual during the interview (job satisfaction only), occupation and wave. Full results available in a further technical appendix available via the journal website.

Standard errors are indicated by vertical black lines. Level of significance indicated by symbols: $\times \mathrm{p}<0.001, \Delta \mathrm{p}<0.01, \square \mathrm{p}<0.05$ 
Table A1 - Unweighted variable means (standard deviation in parentheses for continuous variables)

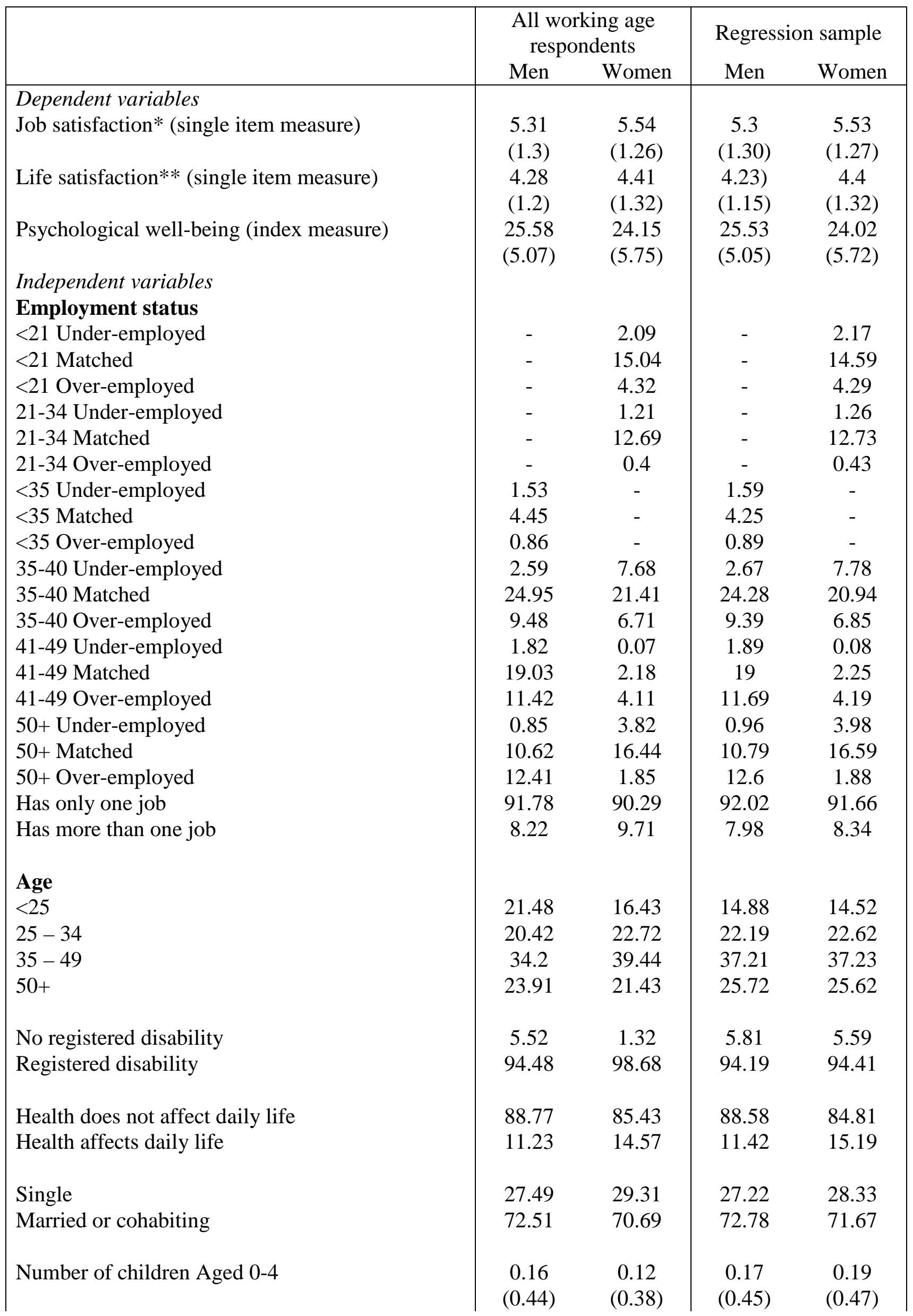




\begin{tabular}{|l|cc|cc|} 
Number of children Aged 5-18 & 0.55 & 0.56 & 0.52 & 0.61 \\
& $(0.92)$ & $(0.74)$ & $(0.88)$ & $(0.92)$ \\
& 7.72 & 7.83 & 7.76 & 7.63 \\
Individual interview alone & $(0.79$ & $(0.61)$ & $(0.71)$ & $(0.76)$ \\
another person present during interview & & & & \\
& 58.98 & 62.12 & 57.28 & 57.76 \\
Occupation & 41.02 & 37.88 & 42.72 & 42.24 \\
Professional occupations & & & & \\
Managerial & & & & \\
Associate professional and technical occupations & 15.90 & 10.52 & 17.30 & 8.52 \\
Clerical occupations & 8.62 & 10.71 & 9.35 & 7.39 \\
Skilled manual occupations & 9.12 & 13.04 & 10.00 & 9.52 \\
Personal and protective services & 6.92 & 26.07 & 7.3 & 17.97 \\
Sales occupations & 17.88 & 2 & 19.38 & 1.53 \\
Semi-skilled manual & 5.64 & 16.13 & 5.34 & 11.51 \\
Unskilled & 4.5 & 10.01 & 4.06 & 6.88 \\
& 11.41 & 3.6 & 12.24 & 2.45 \\
\hline Un-weighted N & 6.71 & 8.1 & 6.33 & 5.58 \\
\hline
\end{tabular}

Notes: Standard deviations in parentheses. Column (1) Un-weighted sample of observations from all working age respondents in waves 1-18 of the BHPS. Column (2) Un-weighted sample of observations from respondents who supplied full information for all covariates used in the regression analysis. This excludes waves 9 and 14 because the question on whether health limits daily activities was not included in these waves. Means of independent variables are based upon the un-weighted sample of respondents who supplied information for all covariates used in the regression analysis using psychological well-being as a dependent variable. * - Wave 1 omitted because of inconsistencies in show card labelling between wave 1 and all other waves. ${ }^{* *}$ The question on life satisfaction was only asked in waves 6 to 10 and 12 to 18. 
Table A2 - Observations of anticipation (lags) and duration (leads) of working time mismatch in the BHPS

\begin{tabular}{|c|cc|cc|}
\hline & \multicolumn{2}{|c}{ Over-employment } & \multicolumn{2}{c|}{ Under-employment } \\
\hline & Men & Women & Men & Women \\
\hline 3 years before mismatch & 1195 & 1404 & 273 & 380 \\
2 years before mismatch & 984 & 994 & 266 & 353 \\
1 year before mismatch & 2530 & 2336 & 669 & 842 \\
Mismatched for up to 1 year & 12899 & 12157 & 2254 & 2523 \\
Mismatched 2 years for 1 to 2 years & 1497 & 1371 & 826 & 1102 \\
Mismatched for 2 to 3 years & 658 & 631 & 153 & 402 \\
Mismatched for more than 3 years & 1213 & 1113 & 467 & 393 \\
\hline
\end{tabular}

Notes: un-weighted sample of observations from respondents who reported being mismatched in any of the 18 waves of the survey, who were observed in the 3 waves before and after the mismatch event (or until the mismatch was resolved) and who supplied information for all covariates used in the regression analysis (except the question on whether health limited daily activities, which was not used in model (2) in order to maximise the number of observations and waves included).

\section{Corresponding author:}

Andy Charlwood

School of Business and Economics

Loughborough University

Loughborough

\section{LE11 3TU}

United Kingdom

A.Charlwood@lboro.ac.uk

\section{Other author:}

David Angrave

University of York

York

Yorkshire

United Kingdom 
da519@york.ac.uk 